\title{
Entrepreneurial ecosystem elements
}

\author{
Erik Stam • Andrew van de Ven
}

Accepted: 18 June 2019 /Published online: 11 November 2019

(C) The Author(s) 2019

\begin{abstract}
There is a growing interest in ecosystems as an approach for understanding the context of entrepreneurship at the macro level of an organizational community. It consists of all the interdependent actors and factors that enable and constrain entrepreneurship within a particular territory. Although growing in popularity, the entrepreneurial ecosystem concept remains loosely defined and measured. This paper shows the value of taking a systems view of the context of entrepreneurship: understanding entrepreneurial economies from a systems perspective. We use a systems framework for studying entrepreneurial ecosystems, develop a measurement instrument of its elements, and use this to compose an entrepreneurial ecosystem index to examine the quality of entrepreneurial ecosystems in the Netherlands. We find that the prevalence of high-growth firms in a region is strongly related to the quality of its entrepreneurial ecosystem. Strong interrelationships among the ecosystem elements reveal their interdependence and need for a systems perspective.
\end{abstract}

Keywords Entrepreneurial ecosystem elements · Regional entrepreneurial ecosystems · Entrepreneurial

E. Stam $(\bowtie)$

Utrecht University School of Economics, Utrecht, The Netherlands e-mail: e.stam@uu.nl

A. van de Ven

Carlson School of Management, the University of Minnesota,

Minneapolis, MN, USA

e-mail: avandeve@umn.edu economy · Entrepreneurship · High-growth firms · Systems analysis

JEL classification D2 $\cdot \mathrm{E} 02 \cdot \mathrm{L} 26 \cdot \mathrm{M} 13 \cdot \mathrm{O} 43 \cdot \mathrm{P} 00 \cdot$ $\mathrm{R} 1 \cdot \mathrm{R} 58$

\section{Introduction}

Scholars and practitioners alike are concerned with the quantity and quality of entrepreneurial activity in a society. For example, scholars involved in the Global Entrepreneurship Monitor have documented the prevalence of various forms of entrepreneurial activity across countries and regions (Reynolds et al. 2005; Stam et al. 2011). In addition, policymakers concerned with economic development have sought to identify policy 'levers' with which to encourage higher levels of entrepreneurial activity resulting in economic growth and job creation (Audretsch and Link 2012). Borrowing from biology, the metaphor of an entrepreneurial 'ecosystem' is increasingly used by scholars (Stam 2015; Spigel 2017; Acs et al. 2017) and practitioners (Feld 2012; Isenberg 2010) for understanding the context for entrepreneurship in particular territories (countries, regions, cities). The entrepreneurial ecosystem comprises a set of interdependent actors and factors that are governed in such a way that they enable productive entrepreneurship (Stam 2015). As applied to entrepreneurship in a region, the metaphor is loosely defined, highly undertheorized and not adequately measured (Stam 2015). The purpose of this paper is to develop an operational definition and 
an empirical model for measuring entrepreneurial ecosystem elements and the quality of regional entrepreneurial ecosystems. The model is informed by and extends previous conceptual and empirical work on the functional attributes or indicators of entrepreneurial ecosystems. Using this conceptual framework, we introduce a methodology for measuring entrepreneurial ecosystem elements and the quality of regional entrepreneurial ecosystems and present empirical findings from a study of entrepreneurship in twelve regions of the Netherlands. The paper concludes by discussing the implications of this entrepreneurial framework for advancing theory and policy practice, and how the measurement instrument can be applied in other territories.

\section{The emerging literature on entrepreneurial ecosystems}

The fundamental ideas behind entrepreneurial ecosystems emerged in the 1980s and 1990s as part of a shift in entrepreneurship studies away from individualistic, personality-based research towards a broader community perspective that incorporates the role of social, cultural and economic forces in the entrepreneurship process (Aldrich 1990; Nijkamp 2003; Steyaert and Katz 2004). Van de Ven (1993), for example, argued that individual entrepreneurs cannot command all the resources, institutions, markets and business functions that are required to develop and commercialize their entrepreneurial ventures. Popular folklore notwithstanding, entrepreneurship is a collective achievement that resides not only in the behaviours of individual entrepreneurs, but requires key roles from numerous entrepreneurs in both the public and private sectors to develop an industrial infrastructure that facilitates and constrains innovation.

There is a long legacy of studies on the 'entrepreneurial infrastructure' explaining the influence of regional economic and social factors have over the entrepreneurship process (Pennings 1982; Dubini 1989; Gnyawali and Fogel 1994; Van de Ven 1993; Bahrami and Evans 1995). Building on previous movements that decentred the individual entrepreneur as the sole locus of value creation, the new contextual turn emphasizes the importance of situating the entrepreneurial phenomenon in a broader context that incorporates temporal, spatial, social, organizational and market dimensions of context (Zahra 2007; Zahra et al. 2014; Woolley 2017).
While work on entrepreneurial ecosystems is still in its infancy, there are already several empirical studies showing how a rich entrepreneurial ecosystem enables entrepreneurship and subsequent value creation at the regional level (Fritsch 2013; Tsvetkova 2015; Autio et al. 2014). For example, Mack and Mayer (2016) explore how early entrepreneurial successes in Phoenix, Arizona, has contributed to a persistently strong entrepreneurial ecosystem based on visible success stories, a strong entrepreneurial culture and supportive public policies. Similarly, Spigel's (2017) study of entrepreneurial ecosystems in Waterloo and Calgary, Canada, suggests that while ecosystems can have different structures and origins, their success lies in their ability to create a cohesive social and economic system that supports the creation and growth of new ventures. Other work on regions such as Silicon Valley and Route 128 (Saxenian 1994; Kenney and Von Burg 1999), Washington DC (Feldman 2001) and Kyoto (Aoyama 2009) _ even if not using the precise term 'entrepreneurial ecosystem'-described how contexts influence entrepreneurial success. Works such as Acs et al. (2014) have employed large-scale quantitative methods, rather than qualitative case studies, to identify strong entrepreneurial ecosystems at the national level.

While appealing, the entrepreneurial ecosystem concept is problematic, and the rush to employ it has run ahead of answering several fundamental conceptual, theoretical and empirical questions. The phenomenon at first appears rather tautological: entrepreneurial ecosystems are systems that produce successful entrepreneurship, and where there is a lot of successful entrepreneurship, there is apparently a good entrepreneurial ecosystem. Such tautological reasoning ultimately offers little insight for research or public policy. Secondly, the approach as yet provides only laundry lists of relevant factors without clear reasoning of their cause and effect, nor how they are tied to specific place-based histories. While these factors provide some focus, they offer no consistent explanation of their interdependent effects on entrepreneurship - and, ultimately, on aggregate welfare. The World Economic Forum (2013) study, for example, concludes that access to markets, human capital and finance are most important for the growth of entrepreneurial companies. But these can best be seen as proximate causes, not as the fundamental causes for the success of ecosystems (Acemoglu et al. 2005). An adequate explanation should distinguish between the necessary and contingent conditions of an ecosystem and 
clearly define the role of the government and other institutions. This has not yet been accomplished. And third, it is not clear what is the appropriate level of analysis of an entrepreneurial ecosystem (Malecki 2018). Geographically, it could be a city, a region or a country. It can also be other systems less strictly defined in space, such as sectors or technologies, which create opportunities for firm creation and growth. For most system elements, it seems possible to demarcate them at a regional (sub-national) level (e.g. regional labour markets), while the conditions can be designed on both regional and national levels (e.g. national laws and regulations) (cf. Stam and Bosma 2015). In addition, entrepreneurs of high-growth firms and especially entrepreneurial employees in large established firms could act as ecosystem connectors on a global scale, connecting distinct regional entrepreneurial ecosystems in their role as knowledge integrators (Sternberg 2007; Malecki 2011).

\section{The entrepreneurial ecosystem defined}

There is not yet a widely shared definition of entrepreneurial ecosystems among researchers or practitioners. The first component of the term is entrepreneurial: a process in which opportunities for creating new goods and services are explored, evaluated and exploited (Schumpeter 1934; Shane and Venkataraman 2000). The entrepreneurial ecosystem approach often narrows this entrepreneurship down to 'high-growth start-ups' or 'scale-ups', claiming that this type of entrepreneurship is an important source of innovation, productivity growth and employment (World Economic Forum 2013; Mason and Brown 2014). Empirically, this claim seems too exclusive: networks of innovative start-ups or entrepreneurial employees can also be forms of productive entrepreneurship (Baumol 1993), even failed ventures can be productive for society (Davidsson 2004). However, innovative and growth-oriented entrepreneurship appears to be increasingly emphasized in the entrepreneurship literature (Shane 2009; Stam et al. 2012; Mason and Brown 2014; Henrekson and Sanandaji 2014).

The second component of the term ecosystem borrows from biology, where ecosystem ('ecological system') has been defined as 'a biotic community, its physical environment, and all the interactions possible in the complex of living and nonliving components' (Tansley
1935). When applying the metaphor to an organizational community ecology, Hawley (1950) adopted three core features of ecosystems: co-evolution and mutualistic interdependence among a complex nested system of diverse organizations and actors. As in biological ecology, a community ecology perspective focuses on the co-evolutionary rise and fall of many diverse organizations and institutions that are mutualistically related and perform differentiated but complementary roles that enable emergence, growth and survival as elements of a broader system of community evolution (Astley and Van de Ven 1983; Astley 1985; Freeman and Audia 2006). This mutualistic interdependence includes both cooperative and competitive relationships among partisan, distributed and embedded actors pursuing their own interests in the ecosystem, all of which contribute to the complexity of the system. For example, to start new businesses in a particular region, entrepreneurs develop mutualistic interdependencies for knowledge with scientific communities, for financial resources from venture capitalists and investors, for competent human resources from universities and training institutes, for regulatory approval and licencing from various government departments, for parts and distribution from supply chains, and product sales from informed consumers. Entrepreneurs are not only dependent on these elements; these elements are also dependent on entrepreneurs. All of these actors involved in these elements perform crucial roles in developing and sustaining an entrepreneurial ecosystem.

For organizational ecologists, a recognizable community emerges only when the population in a region develops an identifiable cohesion that derives from the mutualistic interdependence among symbiotically related actors with complementary differences (Astley and Van de Ven 1983, p. 258). This necessitates a methodology for studying entrepreneurial ecosystems as a branch of a broader set of complex systems; notably artificial as distinguished from natural systems (Simon 1962). Being human artificial constructions, entrepreneurial ecosystems emphasize the distinct roles of agency and institutions.

The evolutionary process in which actors become engaged in the development of an entrepreneurial ecosystem can begin any number of ways. It varies with the business and technology being developed (Woolley 2017). For example, it can begin with purposeful intentions and inventive ideas of entrepreneurs, who undertake a stream of activities to gain the resources, 
competence and endorsements necessary to develop an economically viable enterprise. As they undertake these activities, the paths of independent entrepreneurs, acting out their own diverse intentions and ideas, intersect. These intersections provide occasions for interaction and recognizing areas for establishing cooperative and competitive relationships. Sometimes these interactions may be triggered by an ecosystem leader (Nambisan and Baron 2013), and sometimes they emerge through a process of partisan mutual adjustment among partisan and distributed actors who become embedded in the ecosystem as it develops over time (Van de Ven and Garud 1993). Partisan mutual adjustment is a form of coordination of people (a) without anybody coordinating them, (b) without a dominant common purpose and (c) without rules that fully prescribe their relations to one another (Lindblom 1965).

Cooperative relationships emerge among the actors who can achieve complementary benefits by integrating their functional specializations. Competitive relationships emerge as alternative business paths become evident and different entrepreneurs 'place their bets on' and pursue alternative paths. We must emphasize that during the initial period of industry emergence, applied research and development is highly uncertain and often dependent on basic science and technology. Depending on the technological alternative chosen by an entrepreneurial individual or firm, it becomes highly dependent on different clusters of basic research institutes, such as universities, laboratories and disciplines, that have been producing and directing the accumulation of basic knowledge, techniques and experience associated with a given technological alternative.

As the number of organizational units and actors gains a critical mass, a complex network of cooperative and competitive relationships begins to accumulate. This network itself becomes recognized as a new field, and takes the form of a hierarchical, loosely coupled system. Of course, hierarchy in an ecosystem is a matter of degree, and some ecosystem components may be only minimally, if at all, hierarchical. Hierarchy is often a consequence of institutional constraints imposed by political and governmental regulatory bodies. Hierarchy also emerges in relationships with key linking-pin organizations who either become dominant industry leaders or control access to critical resources (money, competence, technology) needed by other firms in the ecosystem.
Loose coupling promotes both flexibility and stability to the ecosystem. Links between component subsystems are only as rich or tight as is necessary to ensure the survival of the system (Aldrich and Fiol 1994). In his architecture of complexity, Simon (1962) discussed how a loosely joined system provides short-run independence of subsystems and long-run aggregate dependence. The overall system can be fairly stable, due to the absence of strong ties or links between elements and subsystems, but individual subsystems can be free to adapt quickly to local environmental conditions. Thus, in a complex, heterogeneous and changing environment, a loosely joined ecosystem is highly adaptive.

We view this evolving ecosystem as consisting of the key entrepreneurs and firms that govern, integrate and perform all of the functions required for entrepreneurship to flourish in a territory. The structure of this system, when sufficiently developed, consists of the key elements, which enable particular outputs. As Fig. 1 illustrates, we view productive entrepreneurship as the output of the entrepreneurial ecosystem. Productive entrepreneurship refers to 'any entrepreneurial activity that contributes directly or indirectly to net output of the economy or to the capacity to produce additional output' (Baumol 1993, p. 30). We interpret this as entrepreneurial activity that creates aggregate welfare. This also reflects the mutual interdependence between entrepreneurs and governments, with the latter being concerned with enhancing aggregate welfare, and entrepreneurs being dependent on a context that is shaped by governments.

\section{Entrepreneurial ecosystem model}

As just discussed, an entrepreneurial ecosystem consists of all the elements that are required to sustain entrepreneurship in a particular territory. Van de Ven (1993) was one of the first to propose four broad components of an ecosystem (or what he termed an 'infrastructure') for entrepreneurship, including (1) institutional arrangements that legitimate, regulate and incentivize entrepreneurship; (2) public resource endowments of basic scientific knowledge, financing mechanisms and pools of competent labour; (3) market demand of informed consumers for the products and services offered by entrepreneurs; and of course, (4) proprietary business activities that private entrepreneurs provide through $R \& D$, 


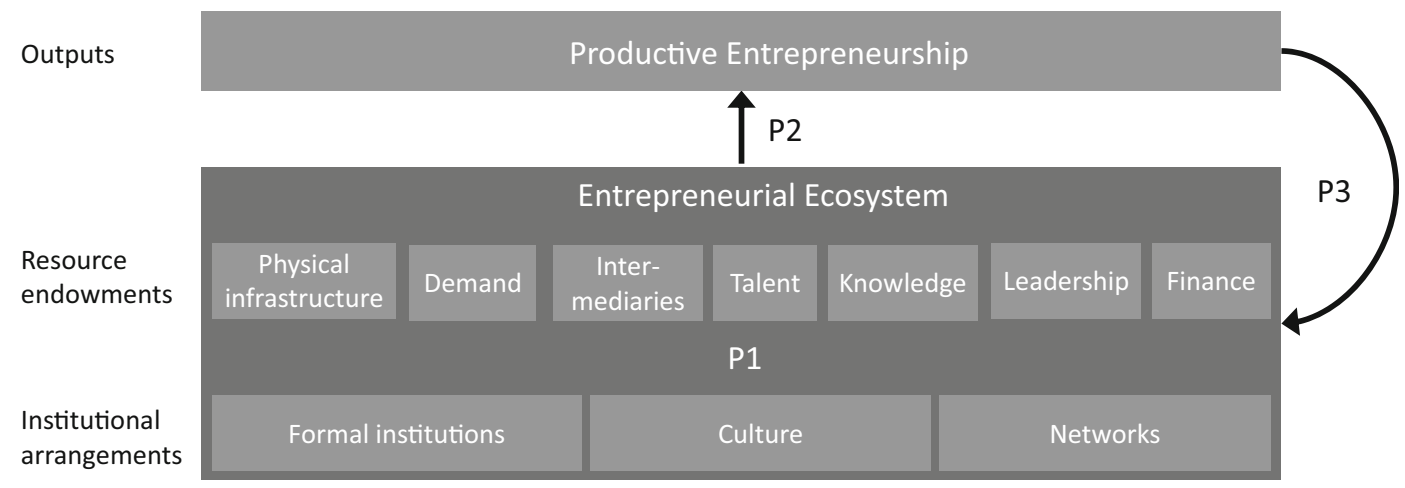

Fig. 1 Elements and outputs of the entrepreneurial ecosystem

manufacturing, marketing and distribution functions (Van de Ven 1993).

Woolley (2017) discusses how scholars have subsequently elaborated and expanded on these elements of an entrepreneurial ecosystem. Feld (2012), for example, emphasized the interaction between the players in the ecosystem (with high network density, many connecting events and large companies collaborating with local start-ups) and access to all kinds of relevant resources (talent, services, capital), with an enabling role of government in the background. Isenberg (2010) formulated six distinct domains of an ecosystem: policy, finance, culture, support, human capital and markets. This largely elaborates Van de Ven's (1993) infrastructure components, as well as eight pillars proposed by the World Economic Forum (2013, pp. 6-7) for a successful ecosystem. These pillars focus on the presence of key factors (resources) like human capital, finance and services; the actors involved in this (talent, investors, mentors/advisors, entrepreneurial peers); the formal ('government and regulatory framework') and informal institutions ('cultural support') enabling entrepreneurship; and finally, access to customers in domestic and foreign markets.

Building on these studies and prior academic studies (see Stam 2015; Stam and Spigel 2018), we propose an integrative model of entrepreneurial ecosystems consisting of ten elements and entrepreneurial outputs (see Fig. 1). The ten elements are operational constructs of the broader concepts of institutions and resources of an entrepreneurial ecosystem. We base our conceptualization on the so-called infrastructure for entrepreneurship (Van de Ven 1993), which is based on a social system framework. Our entrepreneurial ecosystem includes the institutional arrangements and resource endowment components of the infrastructure. The institutional arrangements component is captured by the formal institutions, culture and network elements. The resource endowment component is captured by the physical infrastructure, finance, leadership, talent, knowledge, intermediate services and demand elements. The third component of the infrastructure, proprietary functions, consists of the entrepreneurial firms commercializing innovations. This component is regarded to be the output of the entrepreneurial ecosystem, conceptualized as new value creation and captured by productive entrepreneurship. Table 1 summarizes and relates these concepts, constructs and elements of entrepreneurial ecosystems.

The presence of these elements and the interdependence between them are crucial for the success of the ecosystem (Woolley 2017). Institutions provide the fundamental preconditions for economic action to take place (Granovetter 1992) and for resources to be used productively (Acemoglu et al. 2005). Institutions are not only a precondition for economic action to take place, they also affect the way entrepreneurship is pursued and the welfare consequences of entrepreneurship (Baumol 1990). Networks of entrepreneurs provide an information flow, enabling an effective distribution of knowledge, labour and capital (Malecki 1997).

A highly developed physical infrastructure is a key element of the context to enable economic interaction and entrepreneurship in particular (Audretsch et al. 2015). Access to financing - preferably provided by investors with entrepreneurial knowledge-is crucial for investments in uncertain entrepreneurial projects with a long-term horizon (see e.g. Kerr and Nanda 2009). Leadership provides direction for the entrepreneurial ecosystem. This leadership is critical in building and maintaining a healthy ecosystem (Feldman 2014). This involves a set of 'visible' entrepreneurial leaders 
Table 1 Constructs of entrepreneurial ecosystem elements and outputs

\begin{tabular}{|c|c|c|c|}
\hline Concept & Construct & Definition & Element \\
\hline \multirow[t]{3}{*}{ Institutions } & Formal institutions & The rules of the game in society & Formal institutions \\
\hline & Informal institutions & Cultural context & Culture \\
\hline & Social networks & $\begin{array}{l}\text { The social context of actors, especially the degree to } \\
\text { which they are socially connected }\end{array}$ & Networks \\
\hline \multirow[t]{7}{*}{ Resources } & Physical resources & $\begin{array}{l}\text { The physical context of actors that enables them to meet } \\
\text { other actors in physical proximity }\end{array}$ & Physical infrastructure \\
\hline & Financial resources & $\begin{array}{l}\text { The presence of financial means to invest in activities that } \\
\text { do not yet deliver financial means }\end{array}$ & Finance \\
\hline & Leadership & $\begin{array}{l}\text { Leadership that provides guidance for, and direction of, collective } \\
\text { action }\end{array}$ & Leadership \\
\hline & Human capital & The skills, knowledge and experience possessed by individuals & Talent \\
\hline & Knowledge & Investments in (scientific and technological) knowledge creation & Knowledge \\
\hline & Means of consumption & $\begin{array}{l}\text { The presence of financial means in the population to purchase } \\
\text { goods and services }\end{array}$ & Demand \\
\hline & Producer services & The intermediate service inputs into proprietary functions & Intermediate services \\
\hline $\begin{array}{l}\text { New value } \\
\text { creation }\end{array}$ & $\begin{array}{l}\text { Productive } \\
\quad \text { entrepreneurship }\end{array}$ & $\begin{array}{l}\text { Any entrepreneurial activity that contributes } \\
\text { (in)directly to net output of the economy or to the } \\
\text { capacity to produce additional output }\end{array}$ & $\begin{array}{l}\text { Productive } \\
\quad \text { entrepreneurship }\end{array}$ \\
\hline
\end{tabular}

who are committed to the region (Feldman and Zoller 2012). The high levels of commitment and public spirit of regional leaders might be a reflection of underlying norms dominant in a region (Olberding 2002b). Perhaps the most important element of an effective entrepreneurial ecosystem is the presence of a diverse and skilled group of workers ('talent': see e.g. Acs and Armington 2004; Lee et al. 2004; Qian et al. 2013). An important source of opportunities for entrepreneurship can be found in knowledge, from both public and private organizations (see e.g. Audretsch and Lehmann 2005). There is a conceptual distinction between human capital (talent) and knowledge (Romer 1989; Foray 2004). Human capital includes intangibles like education and experience, while knowledge includes science and technology. In empirical terms, both affect entrepreneurship and aggregate welfare outcomes, but in different ways (Acs et al. 2009; Braunerhjelm et al. 2010). For example, human capital is likely to be necessary to create new knowledge (Romer 1989), and to use new knowledge (cf. the absorptive capacity argument by Cohen and Levinthal 1989). Even though they are conceptually distinct, talent and knowledge are likely to be very interdependent in a regional setting (Qian et al. 2013). The supply of support services by a variety of intermediaries can substantially lower entry barriers for new entrepreneurial projects, and reduce the time to market of innovations (see e.g. Howells 2006; Zhang and Li
2010). Finally, the presence of financial means in the population to purchase goods and services - preferably locally, but possibly also on a further distance-is essential for entrepreneurship to occur at all.

The proposed model extends insights from the previous literature by travelling the ladder of abstraction from theoretical constructs to observable elements of an entrepreneurial ecosystem. Specifically, the entrepreneurial ecosystem causal model is based on three propositions. We emphasize the co-evolution of elements in entrepreneurial ecosystems. Proposition 1 formulates these elements to be mutually interdependent and co-evolve.

Co-evolutionary proposition 1 The entrepreneurial ecosystem elements are mutually interdependent and coevolve in a territory.

With proposition 2, we focus on how the context, measured with the collection of entrepreneurial ecosystem elements in a region, causes productive entrepreneurship that builds upon these elements. We refer to this as upward causation: structure affecting agency.

Upward causation proposition 2 The ten observable entrepreneurial ecosystem elements explain the levels of entrepreneurial activity in a territory.

With proposition 3, we focus on how productive entrepreneurship subsequently affects the entrepreneurial ecosystem, a process we label downward causation: 
agency affecting structure. Examples from the literature are successful entrepreneurs becoming venture capitalists, role models, leaders and network developers in the region (Bosma et al. 2012; Garnsey and Heffernan 2005; Mason and Harrison 2006), which we interpret as positive feedback effects of entrepreneurs on the finance, culture, leadership and network elements of entrepreneurial ecosystems.

Downward causation proposition 3 Prior entrepreneurial activities feedback into entrepreneurial ecosystem elements in a territory.

These propositions are also illustrated in Fig. 1.

\section{Measuring entrepreneurial ecosystem elements and outputs}

Based on the ecosystem concepts and frameworks reviewed above, Stam (2015) developed ten key elements of an entrepreneurial ecosystem (see Table 1). The ten elements represent middle-level constructs. On the one hand, they are reflections of more abstract, underlying concepts (see Section 4). On the other hand, they can be operationalized into variables, a measurable form of these elements. We now turn to definitions and operational measures of variables for the entrepreneurial ecosystem elements. While we intend the conceptual definitions to be generalizable to most entrepreneurial ecosystems, availability of data and empirical indicators may require context-specific measurement of the field setting of a study.

\subsection{Formal institutions}

Formal institutions reflect the rules of the game in society (North 1990). For entrepreneurship, the quality and efficiency of formal institutions matter: the level of perceived corruption and the general regulatory framework within countries. We use data from the Quality of Governance 2012 survey. It consists of data acquired for a large, European Commission-funded project on measuring quality of governance within the EU (Charron et al. 2012). The survey is the largest one ever undertaken to measure quality of governance at the sub-national level so far. It

\footnotetext{
${ }^{1}$ NUTS is an acronym of 'Nomenclature des Unités Territoriales Statistiques', statistical regions in the European Union, with NUTS 1 referring to four groups of Provinces, and NUTS 2 referring to the twelve Provinces in the Netherlands.
}

includes approximately 34,000 EU citizens for a total of 172 regions, either at the NUTS ${ }^{1} 1$ or NUTS 2 level, within the EU member states. Survey questions are focused on four aspects related to three public services (education, healthcare and law enforcement): corruption, rule of law, government effectiveness, and voice and accountability. Four standardized indicators are provided with and used in the 'formal institutions' element of the entrepreneurial ecosystem (for additional details, refer to Charron et al. 2012).

\subsection{Culture}

Entrepreneurship culture (as an informal institution) reflects the degree to which entrepreneurship is valued in society (Fritsch and Wyrwich 2014). Entrepreneurship culture in regions has frequently been measured in quantitative and qualitative ways (Credit et al. 2018). We measure entrepreneurship culture indirectly with the prevalence of new firms, which indicates how 'common' starting up a business is in a particular region.

Entrepreneurship culture could also be measured with the degree to which self-employment is seen as a viable career choice and the degree to which successful entrepreneurs are valued (both derived from the Global Entrepreneurship Monitor). However, this measure is not readily available for regions within the Netherlands.

\subsection{Networks}

Networks of entrepreneurs and their businesses provide an information flow, enabling an effective distribution of knowledge, labour and capital (Malecki 1997). These networks can be measured in many ways (Hoang and Antoncic 2003; Jack 2010). Our analysis focuses on the network structure of businesses in regions. We use a measure of networks that indicates the connectedness of businesses for new value creation: the percentage of businesses (with at least 10 employees) in a region that collaborate for innovation, based on data of the Community Innovation Survey (CIS; see Arundel and Smith 2013). The disadvantage of this measure is that it ignores the networks of micro businesses, but this may be less of a problem for explaining the rate of high-growth firms, which relatively often have grown beyond the size of micro firms. 


\subsection{Physical infrastructure}

Physical infrastructure is a composite measure including indicators of motorway and railway potential accessibility and the number of passenger flights (see Annoni and Dijkstra 2013). Motorway accessibility includes the population living in surrounding regions weighted by travel time along motorways, while railway accessibility includes the population living in surrounding regions weighted by travel time along railways. Motorway and railway potential accessibility indicators take into account ferry networks allowing for correcting islands penalization. Potential accessibility is a construct of two functions, the activity function representing the activities or opportunities to be reached and the impedance function representing the effort, time, distance or cost needed to reach them (Spiekermann et al. 2002). For potential accessibility, the two functions are combined multiplicatively, i.e. they are weights to each other and both are necessary elements of accessibility. The interpretation is that the greater the number of attractive destinations in areas $j$ and the more accessible areas $j$ are from area $i$, the greater the accessibility of area $i$.

The accessibility model used is based on the work of Spiekermann and Wegener (1996) and uses centroids of NUTS 2 regions as origins and destinations. The accessibility model calculates the minimum paths for the road network, i.e. minimum travel times between the centroids of the NUTS 2 regions. For each region, the value of the potential accessibility indicator is calculated by summing up the population in all other regions weighted by the travel time to go there. For access to the region to itself, the time to the centroid of the region is used, while for access to other regions: (i) travel time over the network between the two centroids plus the (ii) access from the destination centroid to the destination region are used. The potential accessibility indicators use population and give the highest weight to the population that can be reached within 4 hrs (Annoni and Dijkstra 2013).

The indicator on passenger flights is from Eurostat/ EuroGeographics/National Statistical Institutes and corresponds to the daily number of passenger flights accessible within a 90-min drive from the region's centre.

\subsection{Demand}

Demand is measured as a composite consisting of disposable income per capita and two measures of potential market demand. Disposable income is included as income per capita. The two indicators on potential market demand provide an estimate of the GDP and population available within a pre-defined neighbourhood. They are expressed respectively in purchasing power standards and population size (EU average set to 100), see Annoni and Kozovska (2010) for details on the computation of potential market demand indicators. Demand might be the element with the least spatial bounds, especially for high-growth firms, which are likely to serve markets beyond the home region.

\subsection{Leadership}

Leadership provides guidance for and direction of collective action. Conceptually and empirically rigorous studies on leadership in regions are still sparse (Sotarauta et al. 2017). Empirically, leadership can be measured with the presence of visible (singular) leaders, but also with more distributed forms of leadership, including the prevalence of privately organized interest groups and (public-private) partnerships for economic development (Olberding 2002a). Leadership is measured with the prevalence of innovation project leaders. We have constructed a database with information on all the innovation projects in the Netherlands that received (Dutch or European) public subsidies in the period 2010-2013 (see Stam et al. 2016). We selected projects with at least two participating organizations (2231 projects). The geographical origin of these projects is established by taking the province of the main applicant or principal firm. This allowed us to measure the prevalence of innovation project leaders per 1000 businesses in each region.

\subsection{Talent}

Human capital and more broadly talent for (productive) entrepreneurship are multifaceted and can be measured in many ways, entrepreneurship specific (see Stam and Spigel 2018) and more generic (Unger et al. 2011). We take the best available generic measure of talent: the prevalence of individuals with high levels of (generic) human capital. This is measured with the share of the population aged 15-65 years with a higher education degree. Talent could also be measured with the share of the labour force with at least secondary education, but we have chosen for the more general, population-based indicator. 


\subsection{Finance}

The supply and accessibility of finance for new and small firms are an important condition for their growth and survival. We use the amount of venture capital (start-up and growth) invested in the region as an indicator for the finance element. This measure is based on data of the National Association for Private Equity, which registers all private equity deals in the Netherlands. We only use the data on the start-up and growth segments (and not on buy-outs, and management buyins), because these are most closely related to the envisaged output of the ecosystem: high-growth firms. Because the annual data on venture capital investments is highly volatile and for some regions based on a very small number of deals, we take a 3-year lagged average per year.

Finance can be traced in many other ways: for example with the ease of access to loans (see Stam 2018), the prevalence of informal investors (Global Entrepreneurship Monitor) and crowdfunding. Data for these measures is available at the national, but not at the regional level, or just for a few years.

\subsection{Knowledge}

Investments in new knowledge are an important source of entrepreneurial opportunities, and if they lead to (better) solutions, they are also a source of prosperity. New knowledge is created in many ways, but probably the best measured activity is investments in (public and private) research and development. Our indicator for the knowledge element is the percentage of gross domestic product invested in $\mathrm{R} \& \mathrm{D}$ (by public and private organizations).

\subsection{Intermediate services}

The supply and accessibility of intermediate business services can substantially lower the barriers and increase the speed of new value creation. Our indicator for intermediate services is the percentage of business service firms in the business population.

The elements are measured with variables that are lagged 1-3 years to the output measure of the entrepreneurial ecosystems, which we will discuss in the next section. The empirical indicators for the elements of entrepreneurial ecosystems are often far from perfect, due to the constraints on the availability of (regionally comparative) data. For example, for culture, we would have preferred more specific entrepreneurship culture indicators, which are available at the national but not at the regional level (Table 2).

\subsection{Entrepreneurship outputs}

A 'healthy' entrepreneurial ecosystem is said to produce entrepreneurship as an output and ultimately aggregate value as outcome. There are no perfect measures of either entrepreneurship or aggregate value creation. To capture both output and outcome, we use the concept of productive entrepreneurship (see Stam 2015; Stam and Spigel 2018), which is related to the (temporally preceding) concept of ambitious entrepreneurship (Stam et al. 2011), and indicates high-quality entrepreneurship (Guzman and Stern 2016).

Prior research has shown that ambitious entrepreneurship has stronger effects on economic growth than other types of entrepreneurship (Stam et al. 2011; Wong et al. 2005), and that young firms are a driver of job creation (Haltiwanger et al. 2013; Criscuolo et al. 2014), and that young high-growth firms accelerate the reallocation of jobs from old to new industries (Bos and Stam 2014). These empirical measures of entrepreneurship can be seen as proxies for productive entrepreneurship. In this paper, we have proxied productive entrepreneurship with the prevalence of high-growth firms (Henrekson and Johansson 2010; OECD 2011; Stam and Bosma 2015). This variable is labelled HGFRIRMS, and indicates the share of high-growth firms of the regional business population. These highgrowth firms are rare, but not so rare as 'unicorns' (privately held start-ups valued over $\$ 1$ billion). Taking unicorns as entrepreneurial output would leave many regions with zero output. We could also start at the other side of the 'entrepreneurship funnel', and count the share of the population that has the intention to start a business, or has just started a business. But we regard this to be an indicator of entrepreneurial culture in a region, not as entrepreneurial output. However, one might take a more process view of entrepreneurial outputs, and differentiate the entrepreneurial ecosystem contexts per phase of the entrepreneurial process (see Stam and Bosma 2015). This is probably most relevant for the finance element, with nascent entrepreneurs, start-ups, moderately growing, high-growth and unicorn firms having substantially different finance needs. 


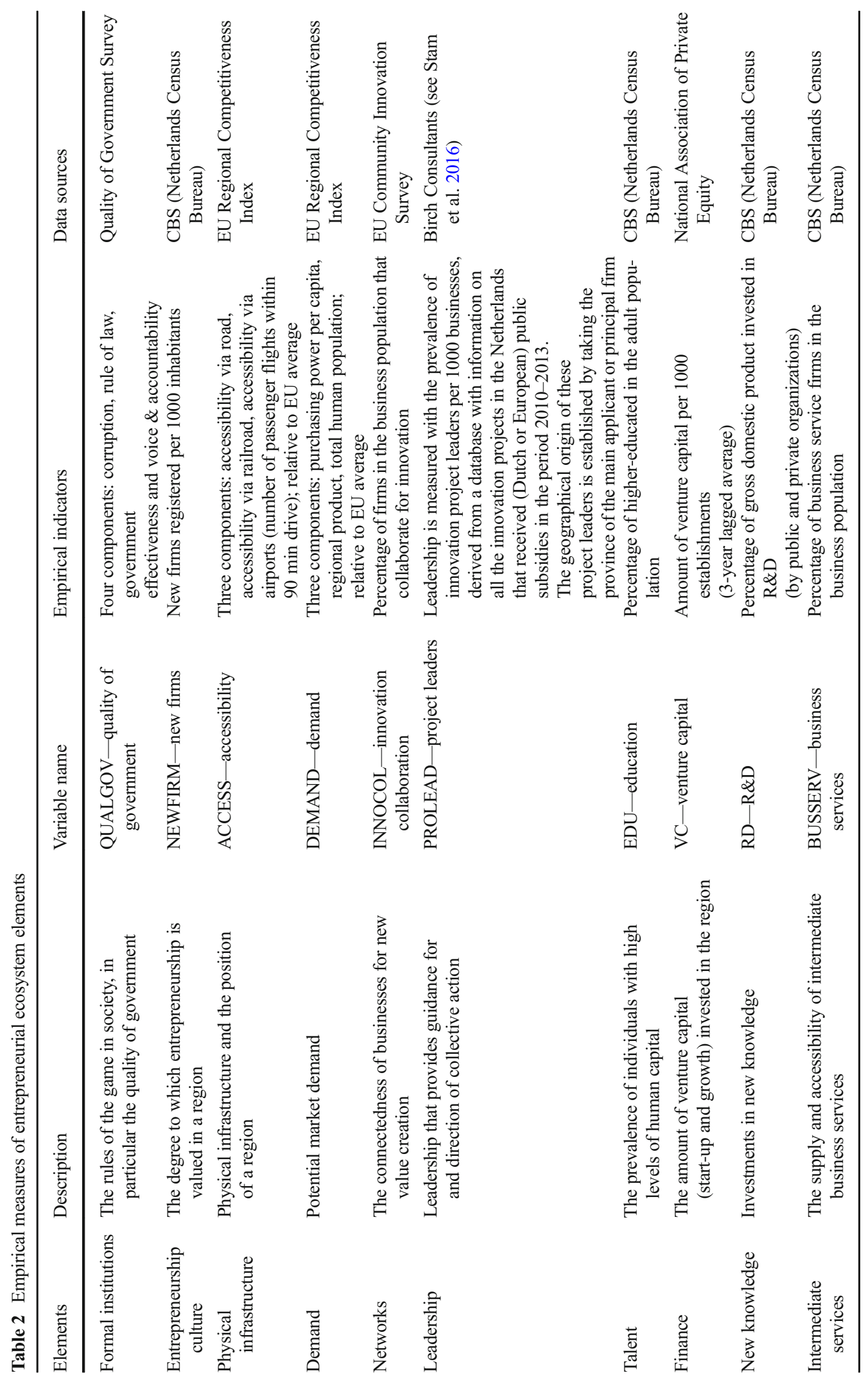


The Dutch Financial Times (Financieele Dagblad), in collaboration with the Chambers of Commerce, has developed a somewhat more selective measure of high-growth firms in the Netherlands: the number of independent firms with a profitable growth in turnover of at least $20 \%$ per year over 3 years (i.e. at least $72.8 \%$ over the full 3 -year period). The selection logic for the 2013 sample is as follows (Financieele Dagblad 2013):

1. There are about 2 million registered firms in the Netherlands

2. 825,000 of these firms are obliged to publish their annual financial details

3. 11,400 of these firms have published annual financial reports

4. Only 1750 of these firms had an average turnover growth of at least $20 \%$ over the last 3 years

5. 784 of these also fulfilled the following requirements: profitable, financial position, payment behaviour

6. After a quality check, 394 high-growth firms remained

There are huge differences across regions, even within a small country like the Netherlands: in 2014, the absolute number of high-growth firms ranges from 1 to 75 , but even in relative terms, there is a 15 -fold difference between the lowest ranked region $0.003 \%$ and the highest ranked region $0.045 \%$.

\subsection{Research context}

These measures, of course, are inevitably influenced by the local context being examined. For this paper, the local context can be characterized as a North-Western European, advanced capitalist economy. More in particular, our research context consists of entrepreneurial ecosystems in twelve regions (provinces: NUTS 2 in European Union terms) of the Netherlands. We have taken the province as the unit of analysis for measuring entrepreneurial ecosystems. It may be debated whether the provincial border provides the most adequate boundary of entrepreneurial ecosystems. The boundaries are almost always arbitrary, most likely somewhere in between the municipality and the national level. Is the province the best unit of analysis, or should entrepreneurial ecosystems perhaps be analysed in a more nested or polycentric (Ostrom 2010) way, further problematizing the territorial view 'borrowed' from the ecological analogy? If we take the openness of the system seriously, this also opens 'explanatory power' of events and elements outside the current regional boundary, affecting the prevalence of entrepreneurship beyond regional boundaries.

\section{Results}

\subsection{Descriptive statistics}

Basic descriptive statistics of the data collected on the entrepreneurial ecosystems in the 12 Netherlands regions for the 3 years $(2009,2012$ and 2015) are presented in Tables 3 and 4. Next to the empirical indicators for the entrepreneurial ecosystem elements, and highgrowth firms, we also introduce a measure for the quality of entrepreneurial ecosystems, the so-called Entrepreneurial Ecosystem Index: EEINDEX. The latter variable will be discussed in Section 6.2.

Table 3 shows the means, minimum and maximum values, and standard deviations of the entrepreneurial ecosystem elements and outputs in 2009, 2012 and 2015. There is substantial variation in the values of the different entrepreneurial ecosystem elements, even within a small country like the Netherlands. Very often, the highest ranked region has an absolute value that is more than double the absolute value of the lowest ranked region. There is also a fifteen-fold difference in the rate of high-growth firms between regions within the Netherlands. This regional heterogeneity in the prevalence of high-growth firms is much more substantial than the heterogeneity in the prevalence of start-ups, as captured with the entrepreneurship culture element (cf. Stam 2005).

Table 4 shows the correlations among the entrepreneurial ecosystem elements and outputs within and across 2009, 2012 and 2015. These correlations provide a first empirical test of co-evolutionary proposition 1 : the entrepreneurial ecosystem elements are mutually interdependent and co-evolve. Several entrepreneurial ecosystem elements are highly correlated in this dataset, as might be expected. There are three clusters of interdependent sets of elements. First, education, new firms and business services are strongly correlated to each other. Second, R\&D and project leaders are strongly correlated. These two clusters reflect key dimensions of the knowledge economy. Third, accessibility and demand are strongly positively correlated, reflecting a 
Table 3 Mean, minima, maxima and standard deviation (normalized values)

\begin{tabular}{|c|c|c|c|c|}
\hline & Minimum & Maximum & Mean & Standard deviation \\
\hline \multicolumn{5}{|l|}{2009} \\
\hline Quality of government & .7970 & 1.2750 & .999917 & .1762263 \\
\hline New firms & .7750 & 1.2950 & .951583 & .1502861 \\
\hline Accessibility & .5470 & 1.3730 & .999667 & .2844888 \\
\hline Demand & .2740 & 1.1910 & .651167 & .3416790 \\
\hline Innovation collaboration & .8858 & 1.0864 & 1.000000 & .0604002 \\
\hline Project leaders & .1900 & 1.4340 & .779583 & .4364244 \\
\hline Venture capital & .1019 & 2.1916 & .829715 & .6351865 \\
\hline Education & .7470 & 1.3140 & .943917 & .1615687 \\
\hline $\mathrm{R} \& \mathrm{D}$ & .2200 & 1.3200 & .850833 & .3397180 \\
\hline Business services & .5600 & 1.3490 & .891250 & .2312594 \\
\hline Entrepreneurial ecosystem index & 5.99 & 12.42 & 8.8985 & 2.11997 \\
\hline High-growth firms & .000313742 & .000849968 & .00054353350 & .000160467163 \\
\hline \multicolumn{5}{|l|}{2012} \\
\hline Quality of government & .80 & 1.28 & .9999 & .17623 \\
\hline New firms & .74 & 1.31 & .9400 & .18742 \\
\hline Accessibility & .23 & 1.95 & 1.0001 & .60954 \\
\hline Demand & .33 & 1.78 & 1.0002 & .48622 \\
\hline Innovation collaboration & .86 & 1.09 & .9999 & .06954 \\
\hline Project leaders & .19 & 1.43 & .7796 & .43642 \\
\hline Venture capital & .01 & 2.33 & .6678 & .64806 \\
\hline Education & .73 & 1.31 & .9461 & .16056 \\
\hline $\mathrm{R} \& \mathrm{D}$ & .28 & 1.32 & .8458 & .32332 \\
\hline Business services & .57 & 1.30 & .8834 & .22500 \\
\hline Entrepreneurial ecosystem index & 5.67 & 12.67 & 9.0628 & 2.40051 \\
\hline High-growth firms & .000074757 & .000488885 & .00023600192 & .000107054815 \\
\hline \multicolumn{5}{|l|}{2015} \\
\hline Quality of government & .94 & 1.15 & 1.0000 & .06112 \\
\hline New firms & .72 & 1.37 & .9274 & .19820 \\
\hline Accessibility & .29 & 2.02 & 1.0000 & .52935 \\
\hline Demand & .39 & 1.79 & 1.0002 & .45831 \\
\hline Innovation collaboration & .96 & 1.07 & .9999 & .03257 \\
\hline Project leaders & .19 & 1.43 & .7796 & .43642 \\
\hline Venture capital & .10 & 1.87 & .7489 & .62425 \\
\hline Education & .75 & 1.32 & .9417 & .16239 \\
\hline $\mathrm{R} \& \mathrm{D}$ & .29 & 1.36 & .8450 & .32798 \\
\hline Business services & .57 & 1.25 & .8914 & .20267 \\
\hline Entrepreneurial ecosystem index & 5.86 & 13.06 & 9.1334 & 2.23085 \\
\hline High-growth firms & .000075339 & .000474515 & .00028787025 & .000135948113 \\
\hline
\end{tabular}

population (prosperity and movement) dimension. Remarkably, quality of government is consistently negatively correlated with the other elements. Overall, we find substantial evidence for our co-evolutionary proposition 1 that the entrepreneurial ecosystem elements are mutually interdependent and co-evolve. The interdependence of the elements is also shown in an interdependence web in Fig. 2 (based on the 2009 data). 

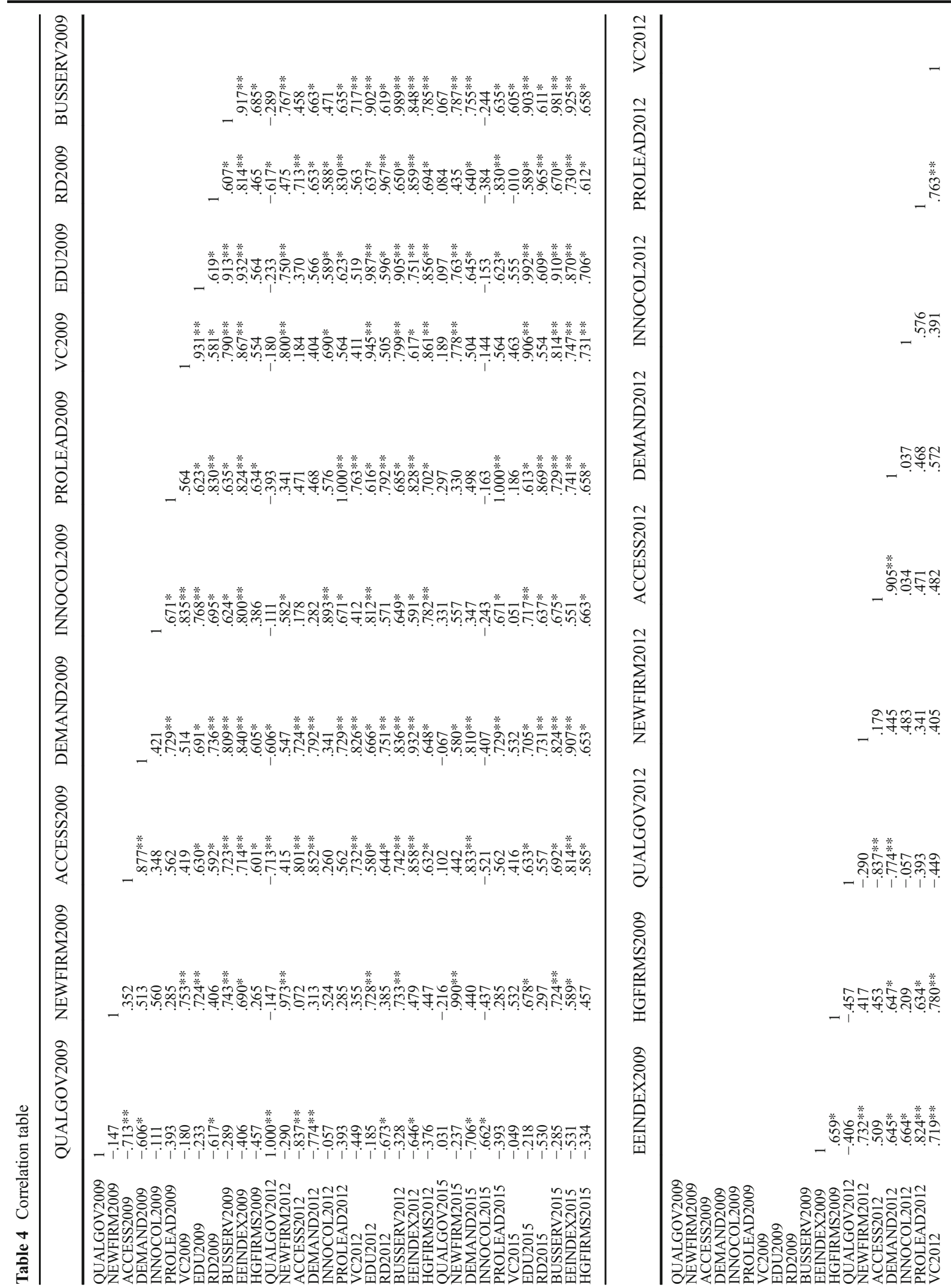

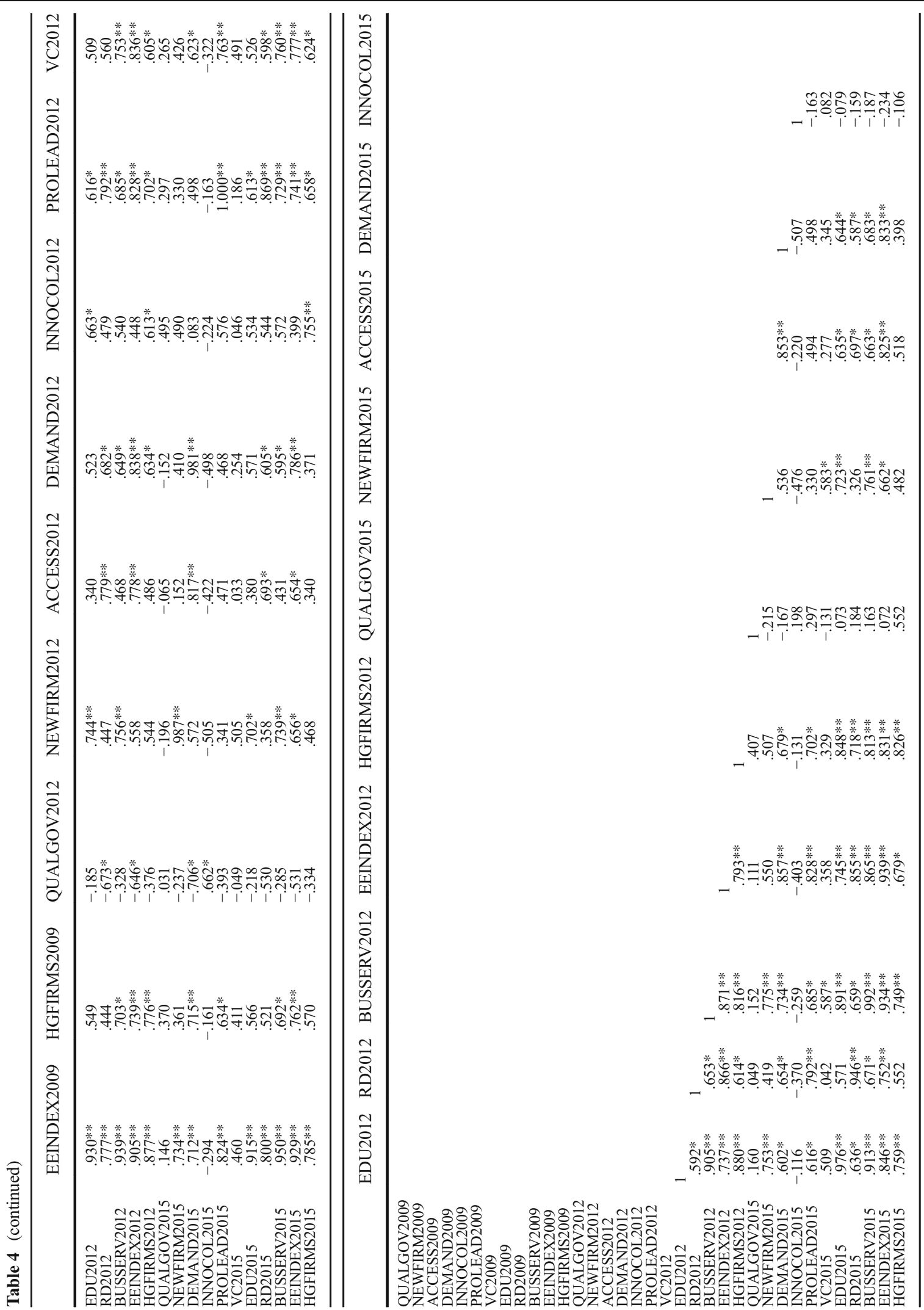


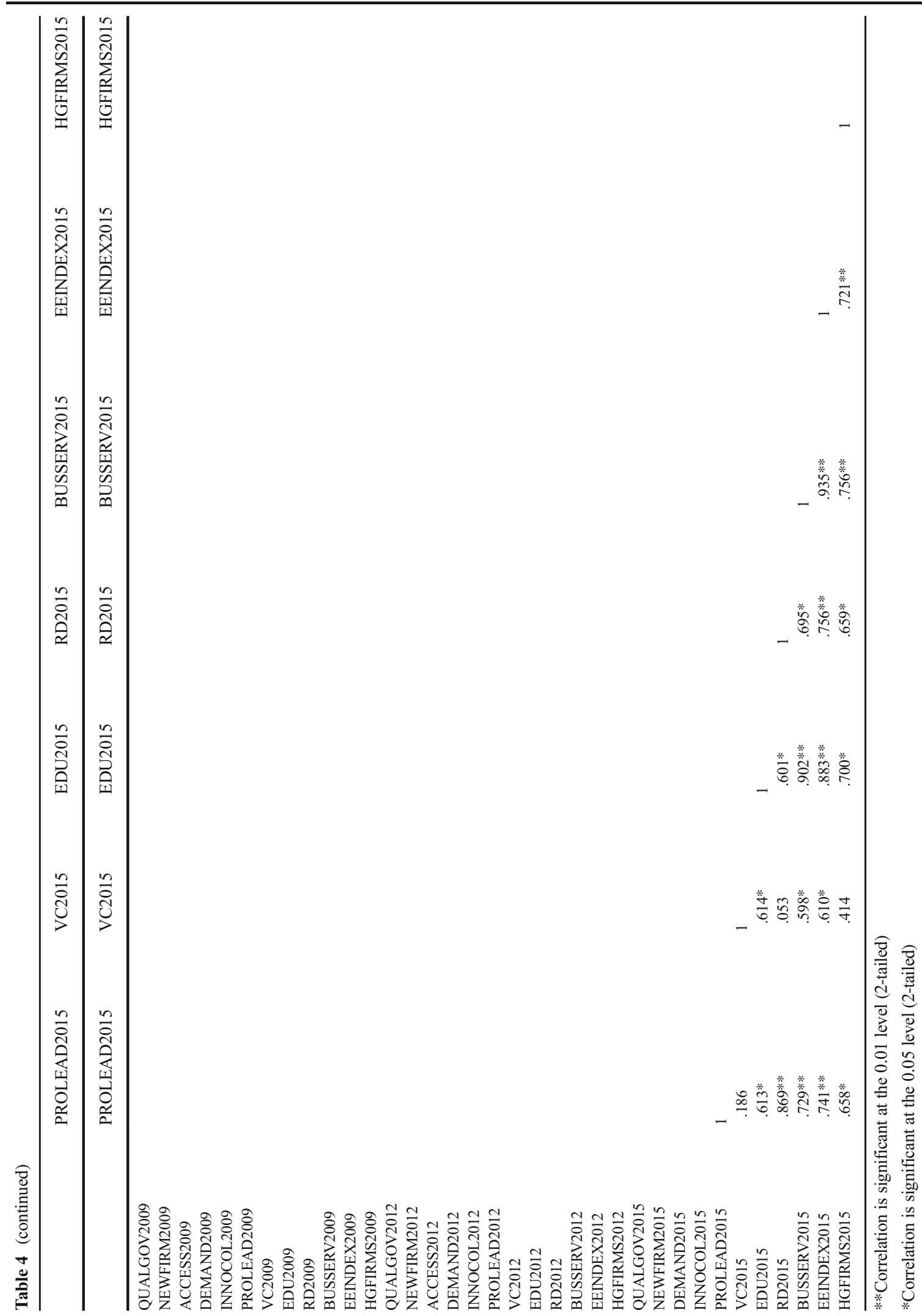


Fig. 2 Interdependence web of entrepreneurial ecosystem elements (2009)

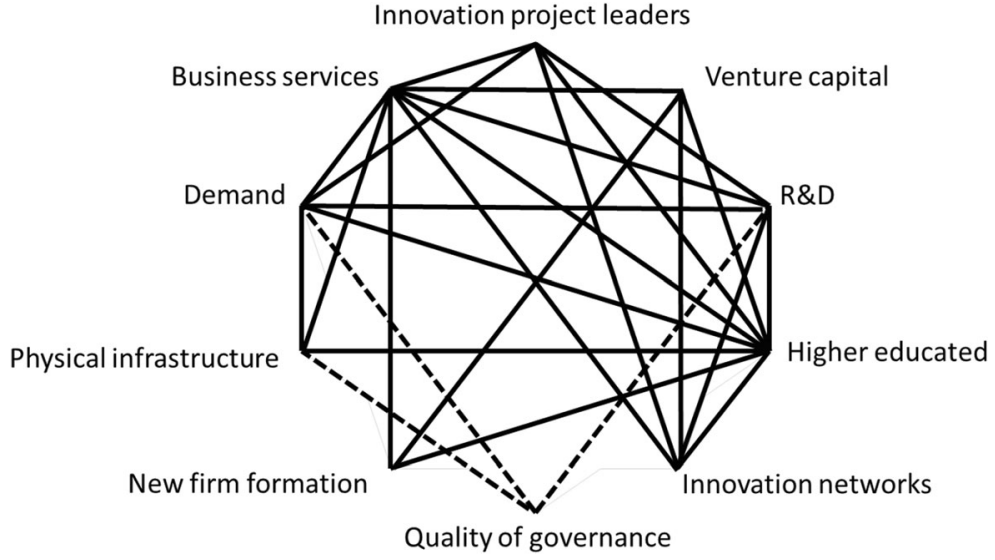

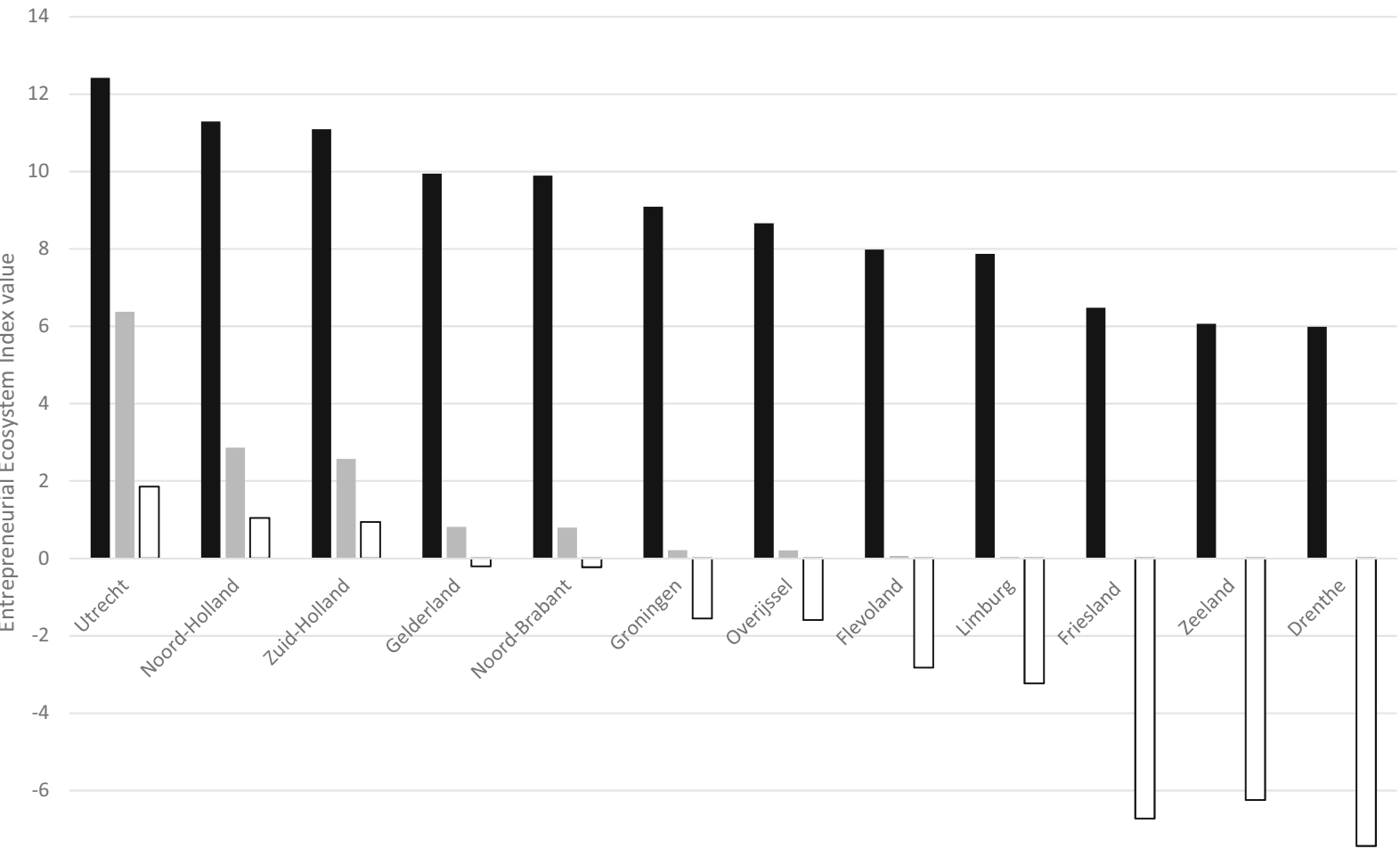

Regions

- additive multiplicative $\square$ natural logarithm

Fig. 3 Entrepreneurial ecosystem index values in the Netherlands regions (2009) 
Fig. 4 Entrepreneurial ecosystem index and the prevalence of high-growth firms in the Netherlands regions (2009)

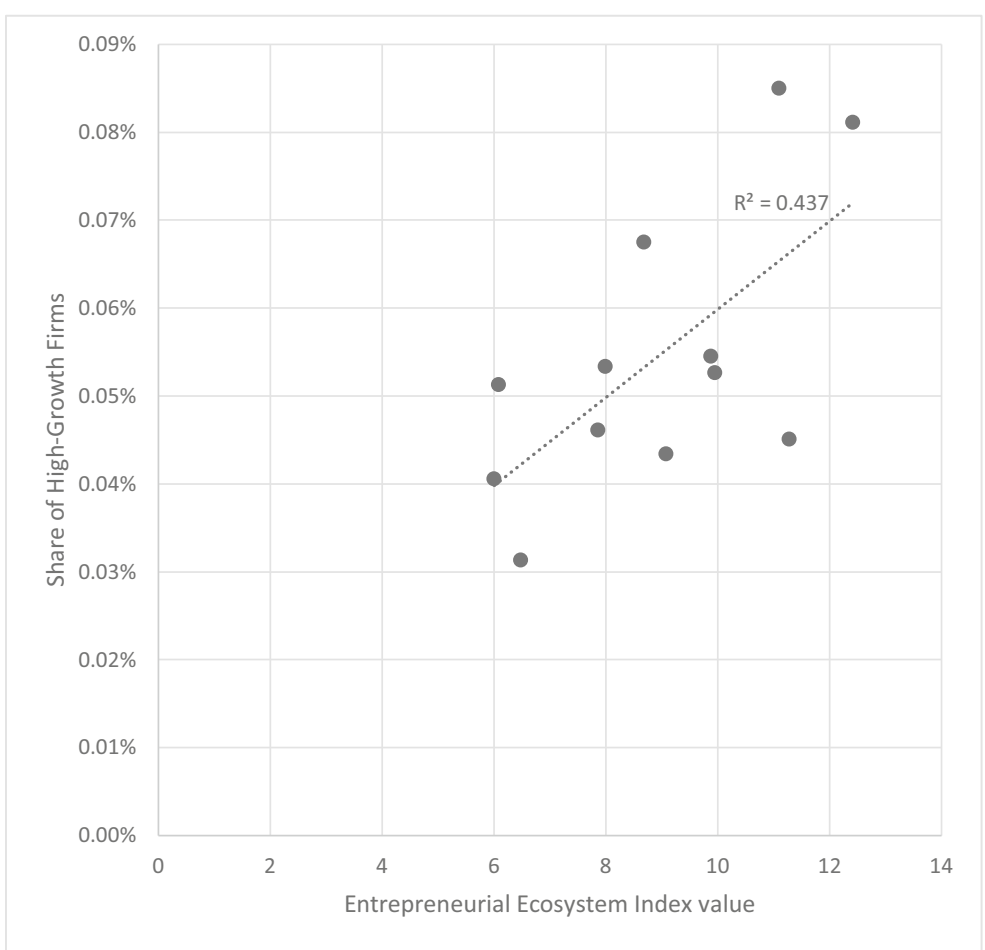

The straight lines indicate a positive correlation of at least 0.6 , and the dotted lines indicate a negative correlation of at least 0.6 . Figure 2 shows that the education and business services elements are most often correlated to other elements.

We performed principal component analyses to uncover dimensions underlying the ten elements (results available upon request). These analyses revealed the dominance of one dimension which covered all elements, but formal institutions, in 2009 and 2012, and all elements, but formal institutions and networks in 2015.

The correlations in Table 4 show that only one of the elements is consistently (positively) statistically related to subsequent prevalence of high-growth firms, namely business services. We will more extensively analyse upward causation proposition 2 below, but first focus on the downward causation proposition 3: prior entrepreneurial activities feedback to increase entrepreneurial ecosystem elements in a territory. The correlations in Table 4 reveal some evidence for downward causation as formulated in proposition 3 . We find positive feedback effects of the prevalence of high-growth firms on most of the subsequent values of the ecosystem elements, although not consistently in all the periods. The prevalence of high-growth firms is consistently correlated with subsequent levels of demand, prevalence of project leadership, and of business services. We also find strong positive correlations between the rates of high-growth firms in 2009-2012 and 2012-2015.

The established empirical literature on the geography of entrepreneurship and economic development has revealed several factors to be of relevance in explaining the spatial heterogeneity in entrepreneurship (see Fritsch 2013; Sternberg 2009; Stam 2010; Stam and Spigel 2018). This suggests that there is a limited set of factors, or elements that affects the prevalence of entrepreneurship in a region. The 'standard' methodological procedure in social science for tracing the effects of individual independent variables, controlling for the effects of the other independent variables, is a multivariate regression model. However, because of its inherent connectivity, nonlinearity and openness, a complex system affords limited functional decomposability (Martin and Sunley 2007), which suggests that the overall functioning of the entrepreneurial ecosystem cannot be deduced from 
knowledge of the function of its elements. Decomposing the entrepreneurial ecosystem into a set of elements and then regressing these on the output of the entrepreneurial ecosystem is not adequate for both substantive and statistical reasons. The substantive reason is that the entrepreneurial ecosystem should be treated as one system, not as set of independent elements. In an ecosystem, there are no direct, one-to-one relationships. The statistical reason comprises the multicollinearity between the individual elements (see Table 4 and Fig. 2). By constructing an index value, also by multiplying the composing elements (see Fig. 3), we do more justice to the systemic nature of the ecosystem than can be done with traditional multivariate regressions.

In the next section, we will take a systems analytical strategy, and analyse how the prevalence of high-growth firms relates to the entrepreneurial ecosystem index.

\subsection{Entrepreneurial ecosystem index}

On the basis of existing geography of entrepreneurship studies (see Stam 2010, 2015; Stam and Spigel 2018), an entrepreneurial ecosystem index is constructed based on ten elements. The elements that are foundational to the entrepreneurial ecosystem index are listed in Tables 1 and 2. The index compresses a large amount of data: the Dutch entrepreneurial ecosystem index, with twelve regions (units), is based on ten thousands of data points (for example the value of the leadership element is based on 2231 innovation projects). For mapping the quality of entrepreneurial ecosystems, we have constructed an entrepreneurial ecosystem index. The index is created to compare different spatial units and a rank in terms of multiple features (elements). The spatial unit may be regions or countries, depending on the (policy) audience to which it is targeted and/or which spatial unit of analysis most adequately covers the relevant mechanisms in the context of entrepreneurship. Since one unit is stronger in one particular feature and the other in another feature, it is necessary to find a universal way to compare and summarize them in one index.

The ten elements of the entrepreneurial ecosystem can be quantified, and be given a comparable value. This is done by normalizing the average value of each element to 1 and then let all deviations be relative to one: with elements in regions performing less than the average having a value below 1 , and elements in regions performing better than the average having a value above
1. The advantage is that this allows us to compose an index value, and compare the quality of different entrepreneurial ecosystems. This index value is computed in an additive way $(\mathrm{E} 1+\mathrm{E} 2+\ldots \mathrm{En})$. The elements of the index all get the same weight. In a later research phase, other weighting techniques than the equal weighting methodology may be applied, based on either the opinion of experts or based on statistical properties of the data. The elements are here summed into one index value, which moves around 10 , with regions performing on the average for all elements scoring an index value of 10 , while regions performing above the average for all elements scoring an index value higher than 10 . This is shown in Fig. 3 for provinces in the Netherlands (2009 data), revealing variation from 12.42 (Utrecht) to 5.99 (Drenthe).

The essence of ecosystems is the interaction among its elements. This interaction is not adequately covered when an index is constructed as a sum of its elements. If we take the interactive nature of the system seriously, and the resulting nonlinear relations, the index should be constructed differently. For this, we compute an index that is not additive $(\mathrm{E} 1+\mathrm{E} 2+\ldots \mathrm{En})$ but multiplicative $(\mathrm{E} 1 * \mathrm{E} 2 * \ldots \mathrm{En})$. This leads to index values with much larger variation, as the effect of deviations of the average is now much more substantial. The index values now vary between 0.001 (Drenthe) and 6.376 (Utrecht) (see Fig. 3). This leads to substantially more variation in the index value: the bottom region Drenthe has an index value that is less than $0.01 \%$ of the value of the top performing region Utrecht. This variation is much larger than the 15-fold difference in the prevalence of highgrowth firms in the lowest ranked region $0.003 \%$ and the highest ranked region $0.045 \%$. Even though the multiplicative index better captures the interactive nature of the system, its external validity seems to be insufficient.

The disadvantage of this index construction is that elements with above average value (ranging from 1 to infinity) can have a stronger effect on the index than elements with below average value (ranging from 0 to 1). To solve this, we take the natural logarithm of the elements, so that these symmetrically oscillate around 0 , with negative values for regions below average, and positive values for regions above average. This also means that the total index value oscillates around 0 and not around 10 (see Fig. 3). The index values now vary between -2.52 (Drenthe) and 0.67 (Utrecht). Figure 3 indicates that the five lagging regions deviate the 
most - negatively — with respect to the quality of their entrepreneurial ecosystem.

We also computed the Z-scores for the individual elements to compose an index value. The index value based on the Z-scores led to a similar ranking of the regions as the other index values. Whatever index measure one uses, the rank order of provinces remains largely the same (results available from the authors upon request). We also performed the same analysis with the 2012 and 2015 data revealing qualitatively similar outcomes.

In addition, we executed several robustness checks on the composition of the index: we repeated index calculations with nine elements, to see whether this affected the quality rankings of the entrepreneurial ecosystems. This also did not substantially change the rank orders of the regions (results available from the authors upon request).

To what extent is the prevalence of high-growth firms a function of the quality of the entrepreneurial ecosystem? The first test of this is to see whether there are statistically significant positive correlations between the entrepreneurial ecosystem index and high-growth firms. Table 3 shows that the prevalence of high-growth firms is always strongly positively correlated to values of the entrepreneurial ecosystem index, suggesting upward causation. The second test is to create a linear model with the entrepreneurial ecosystem index as the independent variable and the prevalence of high-growth firms as the dependent variable. Figure 4 shows the scatterplot and the linear relation between these two variables (based on 2009 data). This linear model has an R2 ranging from 0.4370 (in 2009) to 0.6245 (in 2012), and 0.5256 (in 2015), also suggesting upward causation. However, these values should not be taken as full evidence of a causal relation, given potential endogeneity problems. Endogeneity problems are partly confirmed with the analyses for proposition 3, which show that the prevalence of high-growth firms is correlated to subsequent values of several entrepreneurial ecosystem elements.

\section{Discussion}

The aim of our entrepreneurial ecosystem model is not to predict, but to better understand how (entrepreneurial) economies function (Thurik et al. 2013) and in particular how they 'produce' entrepreneurship as an emerging property of the system (Arthur 2013).

\subsection{Propositions}

We find substantial evidence for our evolutionary proposition 1 that the entrepreneurial ecosystem elements are mutually interdependent and co-evolve in a territory. There is strong interdependence in general, and in three clusters of elements in particular. Talent, entrepreneurial culture and support services are strongly correlated, both simultaneously and over time. The same counts for knowledge and leadership (in innovation projects), also reflecting interdependencies in the knowledge economy. We also find strong interdependencies, both simultaneous and over time, between physical infrastructure and demand. In general, we find very strong positive intertemporal correlations of the values of the individual elements, suggesting strong path dependence in the evolution of entrepreneurial ecosystems.

Our analyses reveal evidence for the upward causation as spelled out in proposition 2: the ten entrepreneurial ecosystem elements (combined in one index value) are strongly related to subsequent levels of entrepreneurial activity in a territory. The ecosystem should be treated as a whole system: its overall quality is positively related to entrepreneurial output; it should not be decomposed in ten elements for explaining the relative influence of different elements of the system.

Finally, our analyses reveal evidence for downward causation as formulated in proposition 3: prior entrepreneurial activities feedback into entrepreneurial ecosystem elements in a territory. We find positive feedback effects of the prevalence of high-growth firms on most of the subsequent values of the ecosystem elements, although not consistently in all the periods. We also find strong positive correlations between the rate of highgrowth firms at $\mathrm{T} 0$ and the rate at $\mathrm{T} 3$. The lack of consistent evidence for temporal feedback might be related to our crude, relatively short-term (3-year lagged) analysis of the presumed feedback effects. More refined in-depth qualitative research might reveal that founders of high-growth firms, later in life become active as leader or venture capitalist in their region, which is not captured in our data.

The tests of our propositions should not be seen as direct tests of causal mechanisms, but as indications of tendencies, derived from a very specific setting in time and space. 


\subsection{A systems perspective}

As noted before, most studies of the context of entrepreneurship have been qualitative case studies that provide rich descriptions of entrepreneurial ecosystem constructs and elements, but do not provide information about how these constructs and elements are related to each other and to entrepreneurial outcomes. This study took a quantitative approach to empirically defining and measuring how these elements are statistically related. In doing so, we found that the empirical indicators of ten ecosystem elements are very highly correlated and that a combined index of these elements statistically explains large variations in entrepreneurial outcomes in Dutch regions. Indeed, these high correlations provide strong evidence for the value of a systemic approach to understanding entrepreneurial ecosystems.

Such a systems approach goes back to Simon (1962) who described complex organizational systems as (nearly) decomposable into subsystems in which a limited number of elements interact more directly with one another than they do with other elements of the system beyond the boundaries of the subsystem concerned. A systems approach focuses on the emergence of effects at the level of the entire system, and looks at the relative performance outcomes of entire sets of multiple elements (Drazin and Van de Ven 1985). The focus is on the working of the entire system of factors.

With the construction of an entrepreneurial ecosystem index, we have quantitatively captured the systemic nature of entrepreneurial ecosystems. This quantitative approach provides a complement to qualitative approaches that identify and describe entrepreneurial ecosystems as sets of multiple characteristics (Mack and Mayer 2016; Spigel 2017). In the future, studies could identify whether a particular number, proportion or combination of factors is in place, and use Boolean comparative analysis (Ragin 1987; Mahoney 2003) to trace causal relations in the evolution of entrepreneurial ecosystems. One recent example of this, applying fuzzyset qualitative comparative analysis is Vedula and Fitza (2019), revealing the configurations of regional factors associated with high levels of (venture-backed) entrepreneurial activity in the U.S. regions.

The systems model of an entrepreneurial ecosystem developed in this paper has important implications for entrepreneurship theory and practice. First, it requires scholars and policy makers to become more sensitive to the macro context of entrepreneurship; too often context has been treated as 'exogenous' where it is not included in the conceptual framework, but 'taken for granted, its influence underappreciated or ... controlled away' (Welter 2011, pp. 173-4). As a result, previous work in entrepreneurship has tended to overlook the role of context in order to produce generalizable models of entrepreneurial activity when instead context should be the specific focus of investigation. A context such as location should not be treated as a simple control variable or proxy; a deeper examination is required of how cultural, social, political and economic structures and processes associated with a region influence all aspects of the entrepreneurial ecosystem.

Second, the ecosystem concept emphasizes that entrepreneurship is not limited to the for-profit sector; numerous entrepreneurial actors in the public and notfor-profit sectors play crucial roles in facilitating or constraining elements of an ecosystem. By understanding the roles of diverse actors and how they interact to develop an entrepreneurial ecosystem, future research on the micro-foundations of entrepreneurship can begin to study how the risk, time and cost to an individual entrepreneur are significantly influenced by developments in the ecosystem.

Third, the systems framework has important implications for individual entrepreneurs. It emphasizes that any given entrepreneurial firm is but one actor, able to perform only a limited set of roles, and dependent on many other actors to accomplish all the functions or elements for an ecosystem to thrive. As a consequence, an individual entrepreneur must make strategic choices concerning the kinds of proprietary resource endowments and institutional functions in which it will participate and what other actors it will engage to achieve selfinterest and collective objectives. These strategic choices make clear that the ways entrepreneurial firms choose to allocate their efforts are variables and that the lines separating the firm from its entrepreneurial community are not sharply drawn but are fluid and change frequently over time. These choices and transactions evolve over time, not only as a result of individual firm behaviour but just as importantly by the interdependencies that accumulate among firms engaged in numerous components of the emerging ecosystem.

\subsection{Limitations}

Our study of entrepreneurial ecosystems in the twelve Netherlands regions explored how elements of 
entrepreneurial ecosystems can be measured and related to their outputs. Although limited to three data collection waves, we also examined temporal developments in ecosystems over time. In doing so, we moved from the ecosystem metaphor to a complex system model of the entrepreneurial economy, at least from an epistemological point of view (Martin and Sunley 2007). Our analysis is based on a small sample (twelve regions in three points in time, totalling 36 observations) in one specific country (the Netherlands). To arrive at more robust findings, this analysis should be repeated in other regions (for example city regions in larger European countries, the USA or China) and multiple periods (preferably 10 years or more, to trace long-term dynamics). This would also allow for feedback effects of the entrepreneurial output on the entrepreneurial ecosystem. The analyses should also be repeated in other contexts, potentially revealing different relations between the entrepreneurial ecosystem and its output.

We also noted that while the conceptual definitions of constructs and elements to be generalizable to most entrepreneurial ecosystems, availability of data and empirical indicators may require context-specific measurement in the field setting of a study. Some of the measures of ecosystem elements in Dutch regions may not be available in other regions, or better measures might be available in other regions. Hence, at the level of measurement, researchers will need to identify and adopt indigenous indicators of entrepreneurial ecosystem elements and constructs.

Finally, future research should study entrepreneurial ecosystems over a longer period of time than the three data collection waves over a 6-year period in this study. The high intertemporal autocorrelations found in this study indicate longer time periods are needed to examine changes in entrepreneurial ecosystem elements. By doing so, we may find that elements of an ecosystem develop and change unevenly over time. As a result, uneven temporal developments of ecosystem elements may act as bottlenecks inhibiting entrepreneurship in a region (Szerb and Acs 2011). Moreover, the very ecosystem elements that are created to facilitate the emergence of entrepreneurship in one area may hinder subsequent development in other areas. This generative process has a dynamic history of creative destruction (Schumpeter 1934) that is important to study if we are to understand entrepreneurship and economic development.
Acknowledgements The authors would like to thank Bilgehan Uzunca and Friedeman Polzin and the participants of the Oxford University School of Geography and Environment seminar (Oxford, 2017), the Congrès des Économistes Belges, Université Libre de Bruxelles (Brussels, 2017), the IFN Stockholm Conference (Vaxholm, 2018), the Uddevalla Symposium (Luleå, 2018), the Forum Institut fur Mittelstandforschung seminar (Bonn, 2018), National Institute of Science and Technology Policy, Seminar on Entrepreneurship and Innovation (Tokyo, 2018), the University of Pecs - Regional Innovation and Entrepreneurship Research Center seminar (Pecs, 2019), and the University of Torino Seminar in Economics of Innovation and Knowledge (Turin, 2019) for their helpful comments and constructive feedback on earlier versions of this paper.

Open Access This article is distributed under the terms of the Creative Commons Attribution 4.0 International License (http:// creativecommons.org/licenses/by/4.0/), which permits unrestricted use, distribution, and reproduction in any medium, provided you give appropriate credit to the original author(s) and the source, provide a link to the Creative Commons license, and indicate if changes were made.

\section{References}

Acemoglu, D., Johnson, S., \& Robinson, J.A. (2005). Institutions as a fundamental cause of long-run growth. In: Aghion, P. \& Durlauf, S. (ed) Handbook of economic growth. Amsterdam: Elsevier.

Acs, Z. J., \& Armington, C. (2004). The impact of geographic differences in human capital on service firm formation rates. Journal of Urban Economics, 56(2), 244-278.

Acs, Z. J., Braunerhjelm, P., Audretsch, D. B., \& Carlsson, B. (2009). The knowledge spillover theory of entrepreneurship. Small Business Economics, 32(1), 15-30.

Acs, Z. J., Autio, E., \& Szerb, L. (2014). National systems of entrepreneurship: Measurement issues and policy implications. Research Policy, 43(3), 476-449.

Acs, Z. J., Stam, E., Audretsch, D. B., \& O’Connor, A. (2017). The lineages of the entrepreneurial ecosystem approach. Small Business Economics, 49(1), 1-10. https://doi. org/10.1007/s11187-017-9864-8.

Aldrich, H. E. (1990). Using ecological perspective to study organizational founding rates. Entrepreneurship Theory and Practice, 14(3), 7-24.

Aldrich, H. E., \& Fiol, C. M. (1994). Fools rush in? The institutional context of industry creation. Academy of Management Review, 19(4), 645-670.

Annoni, P., \& Dijkstra, L. (2013). EU regional competitiveness index RCI 2013. Brussels: European Commission: Brussels.

Annoni, P., \& Kozovska, K. (2010). EU regional competitiveness index 2010. Brussels: European Commission, Joint Research Centre.

Aoyama, Y. (2009). Entrepreneurship and regional culture: the case of Hamamtsu and Kyoto, Japan. Regional Studies, 43(3), 495-512. 
Arthur, W. B. (2013). Complexity economics: A different framework for economic thought. Santa Fe Institute Working Paper.

Arundel, A., \& Smith, K. (2013). History of the community innovation survey. In F. Gault (Ed.), Handbook of innovation indicators and measurement (pp. 60-87). Cheltenham: Edward Elgar.

Astley, W. G. (1985). The two ecologies: population and community perspectives on organizational evolution. Administrative Science Quarterly, 30, 224-241.

Astley, W. G., \& Van de Ven, A. H. (1983). Central perspectives and debates in organization theory. Administrative Science Quarterly, 28, 245-273.

Audretsch, D. B., \& Lehmann, E. E. (2005). Does the knowledge spillover theory of entrepreneurship hold for regions? Research Policy, 34(8), 1191-1202.

Audretsch, D., \& Link, A. (2012). Entrepreneurship and innovation: public policy frameworks. Journal of Technology Transfer, 37, 1-17.

Audretsch, D., Heger, D., \& Veith, T. (2015). Infrastructure and entrepreneurship. Small Business Economics, 44(2), 219230.

Autio, E., Kenny, M., Mustar, P., Siegel, D., \& Wright, M. (2014). Entrepreneurial innovation: the importance of context. Research Policy, 43, 1097-1108.

Bahrami, H., \& Evans, S. (1995). Flexible re-cycling and hightechnology entrepreneurship. California Management Review, 37, 62-89.

Baumol, W. J. (1990). Entrepreneurship: productive, unproductive, and destructive. Journal of Political Economy, 98(5), 893-921.

Baumol, W. J. (1993). Entrepreneurship, management and the structure of payoffs. London: MIT Press.

Bos, J. W., \& Stam, E. (2014). Gazelles and industry growth: a study of young high-growth firms in the Netherlands. Industrial and Corporate Change, 23(1), 145-169.

Bosma, N., Hessels, J., Schutjens, V., Van Praag, M., \& Verheul, I. (2012). Entrepreneurship and role models. Journal of Economic Psychology, 33(2), 410-424.

Braunerhjelm, P., Acs, Z. J., Audretsch, D. B., \& Carlsson, B. (2010). The missing link: knowledge diffusion and entrepreneurship in endogenous growth. Small Business Economics, 34(2), 105-125.

Charron, N., Lapuente, V. \& Dijkstra, L. (2012). Regional governance matters: A study on regional variation in quality of government within the EU. Brussels: DG Regional Policy Working papers WP01/2012.

Cohen, W. M., \& Levinthal, D. A. (1989). Innovation and learning: the two faces of R \& D. The Economic Journal, 99(397), 569-596.

Credit, K., Mack, E. A., \& Mayer, H. (2018). State of the field: Data and metrics for geographic analyses of entrepreneurial ecosystems. Geography Compass, 12(9), e12380.

Criscuolo, C., Gal, P. N., \& Menon, C. (2014). The dynamics of employment growth. Paris: OECD.

Davidsson, P. (2004). Researching entrepreneurship. New York: Springer.

Dubini, P. (1989). The influence of motivations and environment on business start-ups: Some hints for public policies. Journal of Business Venturing, 4(1), 11-26.
Drazin, R., \& Van de Ven, A. H. (1985). Alternative forms of fit in contingency theory. Administrative science quarterly, 514539.

Feld, B. (2012). Startup communities: Building an entrepreneurial ecosystem in your city. New York: Wiley.

Feldman, M. P. (2001). The entrepreneurial event revisited: firm formation in a regional context. Industrial and Corporate Change, 10(4), 861-891.

Feldman, M. P. (2014). The character of innovative places: entrepreneurial strategy, economic development, and prosperity. Small Business Economics, 43, 9-20.

Feldman, M., \& Zoller, T. D. (2012). Dealmakers in place: social capital connections in regional entrepreneurial economies. Regional Studies, 46(1), 23-37.

Financieele Dagblad. (2013). Gazellen. Amsterdam: FD Media Group.

Foray, D. (2004). Economics of knowledge. Boston: MIT press.

Freeman, J. H., \& Audia, P. G. (2006). Community ecology and the sociology of organizations. Annual Review of Sociology, $32,145-169$.

Fritsch, M. (2013). New business formation and regional development-A survey and assessment of the evidence. Foundations and Trends in Entrepreneurship, 9, 249-364.

Fritsch, M., \& Wyrwich, M. (2014). The long persistence of regional levels of entrepreneurship: Germany, 1925-2005. Regional Studies, 48(6), 955-973.

Garnsey, E., \& Heffernan, P. (2005). High-technology clustering through spin-out and attraction: The Cambridge case. Regional Studies, 39(8), 1127-1144.

Gnyawali, D. R., \& Fogel, D. S. (1994). Environments for entrepreneurship development: key dimensions and research implications. Entrepreneurship Theory and Practice, 18(4), 4363.

Granovetter, M. (1992). Economic institutions as social constructions: a framework for analysis. Acta Sociologica, 35(1), 311.

Guzman, J., \& Stern, S. (2016). The state of American entrepreneurship: New estimates of the quantity and quality of entrepreneurship for 15 US states, 1988-2014. Cambridge: National Bureau of Economic Research (No. w22095).

Haltiwanger, J., Jarmin, R. S., \& Miranda, J. (2013). Who creates jobs? Small versus large versus young. Review of Economics and Statistics, 95(2), 347-361.

Hawley, A. (1950). Human ecology: A theory of community structure. New York: Ronald Press.

Henrekson, M., \& Johansson, D. (2010). Gazelles as job creators: a survey and interpretation of the evidence. Small Business Economics, 35(2), 227-244.

Henrekson, M., \& Sanandaji, T. (2014). Small business activity does not measure entrepreneurship. Proceedings of the National Academy of Sciences, 111(5), 1760-1765.

Hoang, H., \& Antoncic, B. (2003). Network-based research in entrepreneurship: a critical review. Journal of Business Venturing, 18(2), 165-187.

Howells, J. (2006). Intermediation and the role of intermediaries in innovation. Research Policy, 35(5), 715-728.

Isenberg, D. J. (2010). How to start an entrepreneurial revolution. Harvard Business Review, 88(6), 41-50.

Jack, S. L. (2010). Approaches to studying networks: Implications and outcomes. Journal of Business Venturing, 25(1), 120 137. 
Kenney, M., \& Von Burg, U. (1999). Technology, entrepreneurship and path dependence: industrial clustering in Silicon Valley and Route 128. Industrial and Corporate Change, 8(1), 67-103.

Kerr, W. R., \& Nanda, R. (2009). Democratizing entry: banking deregulations, financing constraints, and entrepreneurship. Journal of Financial Economics, 94(1), 124-149.

Lee, S. Y., Florida, R., \& Acs, Z. J. (2004). Creativity and entrepreneurship: a regional analysis of new firm formation. Regional Studies, 38(8), 879-891.

Lindblom, C. E. (1965). The intelligence of democracy: Decision making through mutual adjustment. New York: The Free Press.

Mack, E., \& Mayer, H. (2016). The evolutionary dynamics of entrepreneurial ecosystems. Urban Studies, 53(10), 21182133.

Mahoney, J. (2003). Strategies of causal assessment in comparative historical analysis. In J. Mahoney \& D. Rueschemeyer (Eds.), Comparative historical analysis in the social sciences (pp. 337-372). Cambridge: Cambridge University Press.

Malecki, E. J. (1997). Entrepreneurs, networks, and economic development: A review of recent research. In J. A. Katz (Ed.), Advances in entrepreneurship, firm emergence, and growth (Vol. 3, pp. 57-118). Greenwich: JAI Press.

Malecki, E. J. (2011). Connecting local entrepreneurial ecosystems to global innovation networks: open innovation, double networks and knowledge integration. International Journal of Entrepreneurship and Innovation Management, 14(1), 3659.

Malecki, E. J. (2018). Entrepreneurship and entrepreneurial ecosystems. Geography Compass, 12(3), e12359.

Martin, R., \& Sunley, P. (2007). Complexity thinking and evolutionary economic geography. Journal of Economic Geography, 7(5), 573-601.

Mason, C. M., \& Harrison, R. T. (2006). After the exit: Acquisitions, entrepreneurial recycling and regional economic development. Regional Studies, 40(1), 55-73.

Mason, C., \& Brown, R. (2014). Entrepreneurial ecosystems and growth oriented entrepreneurship. Paris: Final Report to OECD http://lib.davender.com/wp-content/uploads/2015/03 /Entrepreneurial-ecosystems-OECD.pdf

Nambisan, S., \& Baron, R. A. (2013). Entrepreneurship in innovation ecosystems: entrepreneurs' self-regulatory processes and their implications for new venture success. Entrepreneurship Theory \& Practice, 37(5), 1071-1097.

Nijkamp, P. (2003). Entrepreneurship in a modern network economy. Regional Studies, 37(4), 395-405.

North, D. C. (1990). Institutions, institutional change and economic performance. New York: Cambridge University Press.

OECD. (2011). Entrepreneurship at a glance 2011. Paris: OECD Publishing. https://doi.org/10.1787/9789264097711-en.

Olberding, J. C. (2002a). Diving into the "third waves" of regional governance and economic development strategies: a study of regional partnerships for economic development in US metropolitan areas. Economic Development Quarterly, 16(3), 251-272.

Olberding, J. C. (2002b). Does regionalism beget regionalism? The relationship between norms and regional partnerships for economic development. Public Administration Review, 62(4), 480-491.
Ostrom, E. (2010). Beyond markets and states: polycentric governance of complex economic systems. American Economic Review, 100(3), 641-672.

Pennings, J. M. (1982). The urban quality of life and entrepreneurship. Academy of Management Journal, 25(1), 63-79.

Qian, H., Acs, Z. J., \& Stough, R. R. (2013). Regional systems of entrepreneurship: the nexus of human capital, knowledge and new firm formation. Journal of Economic Geography, 13(4), $559-587$.

Ragin, C. C. (1987). The comparative method: Moving beyond qualitative and quantitative strategies. Berkeley: University of California Press.

Reynolds, P., Bosma, N., Autio, E., Hunt, S., De Bono, N., Servais, I., Lopez-Garcia, P., \& Chin, N. (2005). Global entrepreneurship monitor: data collection design and implementation 1998-2003. Small Business Economics, 24(3), 205-231.

Romer, P. M. (1989). Human capital and growth: Theory and evidence. National Bureau of Economic Research. Working paper 3173 .

Saxenian, A. (1994). Regional advantage: Culture and competition in Silicon Valley and Route 128. Cambridge: Harvard University Press.

Schumpeter, J. A. (1934). The theory of economic development. Cambridge: Harvard University Press.

Shane, S. (2009). Why encouraging more people to become entrepreneurs is bad public policy. Small Business Economics, 33(2), 141-149.

Shane, S., \& Venkataraman, S. (2000). The promise of entrepreneurship as a field of research. Academy of Management Review, 25(1), 217-226.

Simon, H. A. (1962). The architecture of complexity. Proceedings of the American Philosophical Society, 106, 467-482.

Sotarauta, M., Beer, A., \& Gibney, J. (2017). Making sense of leadership in urban and regional development. Regional Studies, 51(2), 187-193.

Spiekermann, K., \& Wegener, M. (1996). Trans-European networks and unequal accessibility in Europe. European Journal of Regional Development, 4, 35-42.

Spiekermann, K., Wegener, M., \& Copus, A. (2002). Review of peripherality indices and identification of baseline indicator: Deliverable 1 of AsPIRE-Aspatial peripherality, innovation, and the rural economy. Dortmund/Aberdeen: S\&W, IRPUD, SAC.

Spigel, B. (2017). The relational organization of entrepreneurial ecosystems. Entrepreneurship Theory and Practice, 41, 4972.

Stam, E. (2005). The geography of gazelles in the Netherlands. Tijdschrift voor Economische en Sociale Geografie, 96(1), 121-127.

Stam, E. (2010). Entrepreneurship, evolution and geography. In R. Boschma \& R. L. Martin (Eds.), The handbook of evolutionary economic geography (pp. 307-348). Cheltenham: Edward Elgar.

Stam, E. (2015). Entrepreneurial ecosystems and regional policy: a sympathetic critique. European Planning Studies, 23(9), 1759-1769.

Stam, E., \& Bosma, N. S. (2015). Local policies for high-growth firms. In D. Audretsch, A. Link, \& A. Walshok (Eds.), The Oxford handbook of local competitiveness (pp. 286-305). Oxford: Oxford University Press. 
Stam, E., \& Spigel, B. (2018). Entrepreneurial ecosystems. In R. Blackburn, D. De Clercq, \& J. Heinonen (Eds.), The SAGE handbook of small business and entrepreneurship (pp. 407422). London: SAGE.

Stam, E., Hartog, C., Van Stel, A., \& Thurik, R. (2011). Ambitious entrepreneurship and macro-economic growth. In M. Minniti (Ed.), The dynamics of entrepreneurship. Evidence from the Global Entrepreneurship Monitor Data (pp. 231-249). Oxford: Oxford University Press.

Stam, E., Bosma, N., Van Witteloostuijn, A., De Jong, J., Bogaert, S., Edwards, N., \& Jaspers, F. (2012). Ambitious entrepreneurship. A review of the academic literature and new directions for public policy. The Hague: Advisory Council for Science and Technology Policy (AWT).

Stam, E., Romme, A.G.L., Roso, M., Van den Toren, J.P. \& Van der Starre, B.T. (2016) Knowledge triangles in the Netherlands. An entrepreneurial ecosystem approach. Report for the OECD Technology and Innovation Policy Working Group.

Stam, E. (2018) Measuring Entrepreneurial Ecosystems. In: O'Connor, A., Stam, E., Sussan, F., Audretsch, D.B. (eds) Entrepreneurial Ecosystems. Place-Based Transformations and Transitions. New York: Springer. pp.173-196.

Sternberg, R. (2007). Entrepreneurship, proximity and regional innovation systems. Tijdschrift voor Economische en Sociale Geografie, 98(5), 652-666.

Sternberg, R. (2009). Regional dimensions of entrepreneurship. Foundations and Trends ${ }^{\circledR}$ in Entrepreneurship, 5(4), 211-340.

Steyaert, C., \& Katz, J. (2004). Reclaiming the space of entrepreneurship in society: geographical, discursive and social dimensions. Entrepreneurship and Regional Development, 16(3), 179-196.

Szerb, L. \& Acs, Z.J. (2011). The global entrepreneurship and development index methodology.

Tansley, A. J. (1935). The use and abuse of vegetational concepts and terms. Ecology, 16, 284-307.

Thurik, R., Stam, E., \& Audretsch, D. (2013). The rise of the entrepreneurial economy and the future of dynamic capitalism. Technovation, 33(8-9), 302-310.

Tsvetkova, A. (2015). Innovation, entrepreneurship, and metropolitan economic performance: empirical test of recent theoretical propositions. Economic Development Quarterly, 29(4), 299-316.
Unger, J. M., Rauch, A., Frese, M., \& Rosenbusch, N. (2011). Human capital and entrepreneurial success: a meta-analytical review. Journal of Business Venturing, 26(3), 341-358.

Van de Ven, A. H. (1993). The development of an infrastructure for entrepreneurship. Journal of Business Venturing, 8, 211230.

Van de Ven, A. H., \& Garud, R. (1993). Innovation and industry development: The case of cochlear implants. In R. Burgelman \& R. Rosenbloom (Eds.), Research on technological innovation, management and policy (Vol. 5, pp. 146). Greenwich: JAI Press.

Vedula, S., \& Fitza, M. (2019). Regional recipes: a configurational analysis of the regional entrepreneurial ecosystem for US venture capital-backed startups. Strategy Science, 4(1), 4-24.

Welter, F. (2011). Contextualizing entrepreneurship - conceptual challenges and ways forward. Entrepreneurship Theory and Practice, 35, 165-184.

Wong, P. K., Ho, Y. P., \& Autio, E. (2005). Entrepreneurship, innovation and economic growth: Evidence from GEM data. Small Business Economics, 24(3), 335-350.

Woolley, J. (2017). Infrastructure for entrepreneurship. Oxford Research Encyclopedia of Business and Management. Oxford: Oxford University Press.

World Economic Forum. (2013). Entrepreneurial ecosystems around the globe and company growth dynamics. Davos: World Economic Forum.

Zahra, S. A. (2007). Contextualizing theory building in entrepreneurship research. Journal of Business Venturing, 22(3), 443-452.

Zahra, S. A., Wright, M., \& Abdelgawad, S. G. (2014). Contextualization and the advancement of entrepreneurship research. International Small Business Journal, 32(5), 479500.

Zhang, Y., \& Li, H. (2010). Innovation search of new ventures in a technology cluster: the role of ties with service intermediaries. Strategic Management Journal, 31(1), 88-109.

Publisher's note Springer Nature remains neutral with regard to jurisdictional claims in published maps and institutional affiliations. 